\title{
Indicators of craft specialisation in medieval ceramics from north-west Russia
}

\section{Introduction}

In discussing craft specialisation, we are looking for evidence for the organisation of the production of pottery in a social context, and for ways in which this may have changed over time. A model or typology for the organisation of production was provided by van der Leeuw (1977), in the form of five stages (or 'modes of production') of increasing scale and intensity: household production, individual industry, household industry, village industry and large-scale industry. This was modified by Peacock (1982) for the study of Roman pottery, by the addition of a second dimension, representing the degree of official or élite participation, in the form of military/official production and estate production. Costin $(1991,8-9)$ and Costin and Hagstrum $(1995,620)$ developed this second dimension further by the idea of 'attached' and 'independent' types of specialists, each of which could operate at a range of scales. She also used the concept of the degree of specialisation (the ratio of producers to consumers), and four aspects which can be used to characterise production - context, concentration, scale or constitution, and intensity. These were important in breaking the link between scale and intensity of production, a model which has been criticised by others (e.g. Feinman 1999, who challenged the original model as too 'monolithic' by giving examples of high-intensity craft production at a domestic scale (ibid., 96)).

Costin's aspects of production (1991, 11-18) are worth considering in more detail, because they ask questions of the archaeological record, the answers to which can shed light on the organisation of production. Under context, she contrasts the 'command' 
production of attached specialists, sponsored and managed by élite or governmental institutions or patrons, with independent specialists producing for a general market of potential customers (ibid., 11). Her term concentration refers to the spatial organisation of production - for example, are specialists distributed throughout a community, do they each serve a particular community, or are they nucleated to the extent that one centre may serve several communities? (ibid., 13). Scale describes the size of the production unit, which is commonly determined by considerations of efficiency (ibid., 15). Increasing size can bring economies of scale, but can also incur administrative overheads, thus limiting the optimum size of a unit. Finally, Costin's intensity (ibid., 16) reflects the amount of time producers spend on their craft. The choice of full- or part-time production depends on many factors, such as the scope for alternative activities (e.g. agriculture), the efficiency of a particular strategy, the possibility of scheduling potting activities throughout the year, and the need for and availability of capital investment.

These general issues can be translated into questions specific to the circumstances of medieval Novgorod. Although independent producers is the obvious model, there could be attached specialists if a boyar family employed potters to produce specifically for their estates, rural as well as urban. If their products were also made available on the market, this could be seen as hybrid attached/independent specialisation. The topic of concentration raises questions of the locations of potters in the town or region; do they have a rural or urban location, and are they nucleated or dispersed? The size of a production unit should be reflected in the space devoted to potting activities, and the extent of specialised sub-areas for specific tasks. Intensity can perhaps best be inferred 
from evidence for other activities that are undertaken at the same location as potting, whether purely domestic activities or those relating to other productive processes.

There is considerable interest in identifying changes in modes of production, both within a region and over time, as well as in characterising them. In some respects, this is an easier task, because the measures used to indicate specialisation are relative rather than absolute (Costin 1991, 35). In other words, it is easier to say that one assemblage has more evidence of specialisation than another (through, for example, its level of standardisation), than it is to specify the absolute strength of that evidence. Advances in craft specialisation are often associated in the archaeological literature with the emergence of élites (Peregrine 1991), but this relates to prestige goods and 'attached' specialists.

Over the period we are considering (10th to 15 th century), changes can be expected to occur, but not necessarily in a linear progression; waves or cycles may be observed (Orton 1985). Also, changes may not take place simultaneously across a region, and different modes may co-exist.

\section{Archaeological evidence}

The archaeological record can only provide indirect evidence for answering such questions, and as many different sorts of evidence as possible must be sought, to try to build a coherent picture. Four broad sources of evidence may be looked for: 
1. Structural evidence, e.g. kilns, workshops, ancillary structures such as clay preparation pits. Production waste.

2. Technical evidence from the pottery itself - clay and inclusions, methods of construction, decorative techniques, firing temperature and methods.

3. Standardisation/diversity of the product: variation of form and type within and between assemblages across sites, towns and regions.

4. The scale of production - how many pots were being made?

\section{Structural evidence}

Permanent kilns (gorns) and ancillary structures are one of the clearest forms of evidence for production beyond the household level, but none have yet been found, in Novgorod (Gaidukov, pers. comm.), in Pskov (Kildyushevskii 2006, 85), or in Torzhok (Malygin, pers. comm.). This is not a purely regional phenomenon; large medieval settlements elsewhere have also failed to reveal evidence of pottery production within the settlement, for example southern England (e.g. Winchester, Southampton, Chichester, Salisbury) in the medieval period, or Vijayanagara in south India (Sinopoli 1999, 119). The general view in north-west Russia is that kilns would have been located outside towns, for reasons of the fire hazard that they represent, and for access to resources (clay, fuel, water). Certainly, there are abundant resources of good potting clay in the immediate vicinity of Novgorod and at Ryurik Gorodishche, where potting may also have taken place (Plokhov 2006, 13). 
The possibility of firing pots in domestic stoves (pechs) has also been suggested (Kildyushevskii 2006, 86), though this could only be on a small scale and would indicate household production. It is thought that such stoves could achieve a temperature of $600-700^{\circ} \mathrm{C}$, probably below the firing temperature of most of the 'grey' or 'brown' pottery $\left(700-800^{\circ} \mathrm{C}\right.$, see Kildyuskevskii 2006,86$)$ and certainly below that of the 'white' pottery $\left(950^{\circ} \mathrm{C}\right.$; ibid. $)$.

However the pottery was fired, production centres should be characterised by large quantities of production waste, in the form of broken, distorted or over-fired pottery (wasters), as well as ash and possibly fragments of firing structures. No large deposits of such material have been found in either Novgorod or Pskov (Kildyuskevskii 2006, 85), although debris from the production of tiles has been found at Pskov (ibid.). Small quantities of potential waster sherds have been found throughout the material from Troitsky XI, but it has proved extremely difficult to distinguish between genuine wasters and sherds derived from pots that had been destroyed in a house fire. It is also possible that waster sherds in bulk may have had a value in their own right, and may have been moved from their source for such a purpose. Such a practice has been observed by the author at an 18th-century site in Mitcham, London, where large quantities of kiln waste had been moved several kilometres, for use as hard core when the floor level of a building was raised.

Possible production sites should be sought in the immediate hinterland of towns, though admittedly this could be like looking for a needle in a haystack. They are likely to be 
located above the level of spring floods, and could perhaps be found by field-walking for concentrations of sherds, or by magnetometer survey. However, in the short term we must look for other sources of evidence.

\section{Technology}

This is the most common source of evidence, being present in some way on every sherd found. It can be sub-divided into: the clay and inclusions, evidence for forming and finishing, decorative techniques and glaze, and firing.

The pottery generally has substantial additions of filler - up to 20 or 30\% (Brorsson, pers. comm.), although some has inclusions that are naturally present, and a small minority has no inclusions at all. The most common inclusions are crushed granite (gruss) and various grades of sand; grog is also sometimes used. There appear to be chronological trends in the use of different fillers: Kildyushevskii $(2006,83)$ notes that at Pskov, fine, medium and coarse sand predominate in the $12^{\text {th }}$ and $13^{\text {th }}$ centuries, with little gruss; in the $14^{\text {th }}$ and $15^{\text {th }}$ centuries there is more gruss and fine sand, but less medium and coarse sand, while in the $16^{\text {th }}$ and $17^{\text {th }}$ centuries fine and medium sand predominate. In contrast, Brorsson (pers. comm.) notes a trend away from added gruss towards the use of naturally-occurring sand from the $13^{\text {th }}$ century onwards in the samples submitted to them from Novgorod. However, the samples were not selected to be representative of each period, so this pattern may be misleading. Analysis of Orton and Wilson's data suggests that the proportion of sand-tempered pottery at Novgorod did not exceed $10 \%$ in the 13 th century, and was about $40 \%$ in both the 14 th and 15 th centuries. 
Brorsson (pers. comm.) makes the point that clay with gruss inclusions could not have been thrown on a wheel, while clay with sand could have been, and so they see the change from one to the other as reflecting a change to fully wheel-thrown pottery. However, as gruss continues to be used right to the end of the period (see above), the change may have been very gradual.

It is generally agreed that there are three broad stages of development in the forming of pottery: entirely handmade, wheel-finished (usually referred to as wheel-turned in the Russian literature), and fully wheel-thrown. Bobrinskii's seven stages (Bobrinskii 1978; see Goryunova 2006, 32) seem more elaborate than is needed for our purposes here. In the first two stages, pots are built up from wide flat coils of clay (Kildyushevskii 2003, 84; Plokhov 2006, 14). Direct evidence for throwing is best seen in the form of marks on the inside of pots, especially on the lower parts, which are however not always retained from excavations. Russian authors tend to see the step from handmade to wheel-finished as fundamental, while Brorsson (pers. comm.) sees it as a minor change within a conservative tradition, and place more emphasis on the introduction of wheel-throwing, which they place in the $13^{\text {th }}$ century. Kildyuskevskii $(2006,84)$ sees the main advances (wheel-throwing, improved firing techniques, glazing and other finishing techniques) as coming later, in the late 15 th or 16 th and 17 th centuries. This period is poorly represented at Novgorod.

An interesting technical aspect is the use of glaze, whether functional (to seal the surface of a pot) or decorative. Evidence from Pskov (Kildyushevskii 2006, 85) shows that glaze 
was introduced for decorative purposes in the 16th and 17th centuries, linked to the introduction of a range of 'table ware' forms. The timing is probably similar at Novgorod, but this period has been little studied there. Novgorod, however, shows an earlier attempt to introduce glazing (on the inner surface, and therefore presumably functional), in the form of a small group of late-13th-century glazed wasters from the Duboshin site. Although made of local clays (Gaimster 2006, 141), they are similar in style and technique to Baltic ware, and ultimately to the redwares of the Low Countries (ibid.). While this appears to be a failed experiment (in that production did not continue), it is perhaps the best evidence of that date for craft potters who have the resources to attempt to innovate (even if their innovation was not taken up by the consumer). Failed attempts at ceramic innovation are known from other medieval towns, for example from Canterbury (Cotter 1997) and possibly from Exeter (Allan 1984, 27-30) in England. By way of explanation, Gaimster $(2006,141)$ links this attempt to the proximity of Duboshin to the German and Gotland quarters, where more advanced 'western' pottery (stoneware and glazed redwares) was being used by foreign merchants.

\section{Standardisation and diversity}

The more concentrated and centralised the production of pottery, the more 'standard' (or less diverse) the product should be. Diversity should therefore be capable of indicating the level of industrial and/or craft pottery as against domestic potting (with the domestic being the more diverse). The problems with this approach are the level at which diversity is to be measured, and how it is to be measured. Ideally, diversity can be measured by the number of different types (cf. species) in an assemblage, or by their relative proportions. 
This approach gives rise to both theoretical and practical problems (Orton 2000, 171-6), but a specific one here is the meaning of 'type' (compare, for example, Blackman et al 1993, 61). Russian authors generally use a four-level type system, for example classseries-group-type (Koval 2006, 162-4) or group-type-subtype-variant (e.g. Malygin et al 2006, 58), and it is far from obvious which of these levels (if any) is appropriate. The top (Malygin's 'group') level is too high, as it often represents different functional groupings, and the production of a wide range of functional groups is more likely to indicate industrial or craft production. The 'variant' level is likely to be too low, as it represents minor variations which are designated for typological convenience (Malygin, pers. comm.). In fact, the whole typological system is geared towards chronological or functional variation, and is not suited to questions about diversity, which it was never intended to answer.

Decoration might be a more fruitful approach (Hagstrum 1985, 68), since it is less related to function, and might hypothetically be used to differentiate different producers of the same functional type. At both Novgorod and Pskov, the chronological trend is towards simplicity of decoration, with (a) fewer pots being decorated, (b) a smaller area of each pot being decorated, and (c) fewer decorative styles ('combinations') being used together (Kildyushevskii 2006, 110; Rud 2006, 128). This might reflect an increased scale of production and market orientation (Kildyushevskii 2006,111), but there could be other social or ethnic reasons (e.g. less need to assert individuality?). 
Whether one looks at form or decoration (or both), the question can also be asked within or between assemblages. For example, diversity could be expressed by the presence of a wide range of types within an individual site or location, or by differences between different parts of a town or region. The latter might give some idea of the local scale of production, in the sense of the area supplied by a particular producer. However, far more sites will have to be investigated before this approach becomes even remotely possible, and care will have to be taken to distinguish different ethnic groups, for example in the German or Gotlander quarters.

Because of the difficulties of choosing an appropriate level of definition of form type or decoration for studying diversity (see above), alternative variables are sometimes sought. Measurement variables (e.g. height or rim diameter of pots; weight) are attractive because they can be easily defined and reliably recorded. Variability can be measured statistically by use of the standard deviation $(s d)$ or, better, the coefficient of variation $(c v)$. The cv is the sd divided by the mean, and is preferred because it scales variability to the size of the variable (Costin and Hagstrum 1995, 631). For example, a sd of $1 \mathrm{~cm}$ on a diameter of 10 $\mathrm{cm}$ expresses greater variability $(\mathrm{cv}=1 / 10=10 \%)$ than it does on a diameter of $20 \mathrm{~cm}$ $(\mathrm{cv}=1 / 20=5 \%)$. Eerkens and Bettinger $(2001,495)$ have suggested a theoretical lower limit to the cv of $1.7 \%$ as the best that can be achieved in craft processes, due to the limitations of human perception.

The data on rim diameters collected from the ceramic sample of the Troitsky XI excavation, Sector B (Orton 2006, 124) can be used to test this approach. It has already 
been established that average rim diameters vary both between forms and over time (ibid., 125), so variability must be measured for contemporaneous groups of the same form, which can then be compared with other forms of the same date, or the same forms at other dates. For each of the spits that had been catalogued in detail, the means, sds and cvs of the rim diameters were calculated for each form that was well represented in that spit. The cvs were universally large: all were greater than $10 \%$, typical values were between $15 \%$ and $20 \%$, and a few were greater, ranging up to $26 \%$. The only exception is a group of lids that has a cv of only $5 \%$. However, because of the difficulty of distinguishing between the rims of lids and bowls, not too much should be made of this difference. There are no chronological trends in the cvs, and no consistent differences between the cvs of hand-made and wheel-turned types. The scale of the variability strongly suggests that, at any one time, each form was being made in a range of sizes. This observation supports the view of Kildyushevskii (pers. comm.), and may in fact be indirect evidence for specialised production, since manufacture of the same form in a range of sizes suggests production for a number of consumers, while manufacture aimed at just one size may be more typical of domestic production.

\section{Scale of production}

This brings us to the last of our indicators. The actual numbers of pots being produced may give us an idea of how they are produced, with industrial production more prolific than craft production, which in turn is more prolific than domestic production. Normally, such figures would be unobtainable, but the particular circumstances of Novgorod may make it possible to obtain estimates, which although not precise, may suggest the order of 
magnitude. It is thought (pers. comm.) that rubbish was generally disposed of inside the town, and that pottery in particular is concentrated in and around buildings. This being so, it should be possible to estimate the numbers of pots present per unit area or volume, and hence the total 'throughput' of pottery, which can be equated to local production, since imported wares are insignificant in quantity. However, it does not tell us about the numbers of pots in use at any time, because we have no information on use-lives. Once again, we really need a series of samples from across the town to achieve reliable estimates, and so far only one sample area - Sector B of the Troitsky XI excavation - has been recorded in sufficient detail. This area may of course not be representative of density of occupation across the town (in fact, there is evidence that it may not be, see below), but it at least gives a starting point.

The argument proceeds in a series of steps of increasing complexity:

Step 1:

Troitsky XI: 167,000 sherds from $320 \mathrm{~m}^{2} \cong 520$ sherds/sq.m. or about 100 sherds/cu.m. (based on a depth of 26 spits $=5.2 \mathrm{~m}$ ). This pottery density is likely to be too high because the average 'property building density' (i.e. the proportion of each property occupied by buildings) is about 0.25 (Khoroshev et al 2001, 26), but the plan of Troitsky XI (Alexandrovskaya et al 2001, 18) shows that its property building density is considerably greater than this.

Troitsky X: 247,000 sherds from $775 \mathrm{~m}^{2} \cong 320$ sherds/sq.m. or about 60 sherds/cu.m. Nerevsky XV-XXXII: 900,000 sherds from (say) $4000 \mathrm{~m}^{2} \cong 200$ sherds/sq.m. or 40 sherds/cu.m. (depth of excavated deposits $=5 \mathrm{~m}$, Rybina and Khoroshev 2002, 111). 
Take a weighted average of about 50 sherds/cu.m. or 250 sherds/sq.m.; a figure of 80 sherds/pot (Orton 2006, 117) would suggest about 0.6 pots/cu.m. or 3 pots/sq.m.

Taking the area of the medieval town to be about $400 \mathrm{ha}$, and reducing it by $15 \%$ to allow for non-domestic areas (e.g. roads and churches) (Kolchin 1985, 65), would lead to a total of $10.2 \mathrm{~m}$ pots, or about 18,000 p.a. This is only a 'point' estimate, and must be subject to a considerable margin of error. There are two main sources of error: error in the estimate of the number of sherds per cu.m. (point estimate of 50 sherds/cu.m.), and error in the estimate of the number of sherds per pot (point estimate of 80 sherds/pot). Statistical arguments suggest that reasonable 'interval' estimates for these factors would be from 30 to 80 and from 60 to 100 respectively. These can be combined (Orton 2002) to give an overall interval estimate of the total number of pots of between $6.0 \mathrm{~m}$ and $17.5 \mathrm{~m}$ pots (10,000 and 30,000 p.a.).

\section{Step 2:}

The first attempt is too high, as it assumes that the cultural layer has the same depth across the town as it does at Troitsky and Nerevsky (about 5m), which is not the case. Calculations based on a map (Rybina and Khoroshev 2002) that divides Novgorod into 'zones', and the median thicknesses of the cultural layer in sites in each zone, suggest an average depth across Novgorod of about $2.0 \mathrm{~m}$, leading to a revised estimate of about $4.8 \mathrm{~m}$ pots overall, or about 8,400 p.a. Similar arguments to those used in Step 1 lead to an interval estimate of the total number of pots of between $2.4 \mathrm{~m}$ and $7.2 \mathrm{~m}$ pots ( 4300 and 12700 p.a.). 
Step 3:

These calculations are still too simple, as they assume a constant density of pottery (in terms of pots per cu.m. of deposits) throughout the period. Data collected from Troitsky XI (Table 1) shows that this is not the case. In this table, the numbers of rim sherds per spit have been converted to numbers per century, and then to numbers of pots per century, using figures of rim sherds per pot derived from the more detailed cataloguing of the pottery from Sector B. The table shows a relatively low density of pots in the 10th to 12th centuries, followed by a higher density in the 13th and 14th centuries (a more detailed analysis shows that this increase started in the second half of the 12 th century). A relative decline in the 15 th century may be due, at least in part, to disturbance of the 15 thcentury spits (Malygin et al 2006, 74).

Rim sherds

Rim sherds per year

Percentage

Rim sherds per pot

Total pots

Centuries

\begin{tabular}{rrrrrrr}
\multicolumn{7}{c}{ Centuries } \\
10 th & 11 th & 12 th & 13 th & 14 th & 15 th & total \\
2342 & 3114 & 4389 & 5482 & 5848 & 4286 & 25461 \\
33 & 31 & 44 & 55 & 58 & 43 & \\
13 & 12 & 17 & 21 & 22 & 16 & 100 \\
11.8 & 11.5 & 11.5 & 10.7 & 11.3 & 11.3 & \\
198.5 & 270.8 & 381.6 & 512.3 & 517.5 & 379.3 & \\
0.62 & 0.85 & 1.19 & 1.60 & 1.62 & 1.19 &
\end{tabular}

\section{Table 1: density of pottery per century in Troitsky XI}

Considerations from Step 1 suggest that these figures should be halved to be representative of Novgorod as a whole (since the pottery density on Troitsky XI seems to be about twice the notional 'average'). If the depth of deposits can be related to the length of occupation, then the zonal map of deposit thickness can be used to plot the approximate extent of the occupied area within the town on a century-by-century basis. 
The density of pottery in Table 1 can be applied to these areas to give a revised estimate of the total number of pots, which on this basis comes to about $6.9 \mathrm{~m}$, or 12,000 p.a. on average, varying from around 4000 p.a. in the 11 th century to almost 20,000 p.a. in the 13th and 14th centuries. There is insufficient evidence to permit the calculation of interval estimates for these quantities, but they are likely to be of the same order as those for the previous steps.

Kolchin, in a discussion of medieval Russian towns, explains that the average 'ordinary' property or estate had an area of about 400 sq.m., and a population of six occupants (Kolchin, 1985, 64-5). The 'boyar' properties would typically have been from 2.5 to four times this size, with a proportionally greater population. This meant that the population density of the urban area occupied by properties would have been about 120-150 per ha., only about one-third to one-half of that estimated for West European towns at that date, according to Kolchin (ibid.). From this he concludes that the population of Novgorod in the 13 th century (before the Tatar invasion) was unlikely to have exceeded 30 or 35,000 (ibid., 65).

These figures can be compared with the estimates of numbers of pots to give some idea of the intensity of use. The ratio of pots to people in the 13 th century seems to be about 0.6 , i.e. the production of pottery was about 0.6 pots per person per annum. This does not tell us about the number in use at any particular time, as that would depend on the lifespan of the pots, for which we have no information. The ratio is markedly lower in the 
earlier centuries, increasing gradually from around 0.25 in the 10th century, and seems to be static later, perhaps falling off in the 15 th century.

These figures, even allowing for reasonable errors, seem well within the capabilities of domestic production. On the other hand, the production of some 20,000 pots per annum (13th century) would require the resources of several production units (on the basis of 100 pots per firing, one firing every three days for five months of the year - which is optimistic - would imply the regular use of four kilns of say $1.5 \mathrm{~m}$ diameter and $1.0 \mathrm{~m}$ height).

\section{Views on specialisation}

As we have seen in the Technology section, different writers emphasise different aspects of the development of pottery production throughout this period, and thus come to different conclusions about the emergence of specialist craft potters.

Plokhov $(2006,13)$ comments that "Observations by ethnographers show that among the peoples of Eastern Europe hand-made pottery was produced in the home or by craftsmen and was used mainly within the confines of the settlement in which it was made".

Kildyushevskii $(2006,85)$ refers to the craft nature of production in Pskov in the 12th to 17th centuries, citing as evidence "the large series of identical vessels, the very small number of stamps on the bases of vessels and the use of fairly advanced techniques". He does not refer to the earlier material (9th to 12th centuries), as that had already been 
published elsewhere. He also links the decrease in both the quantity and complexity of decoration throughout this period with an increasingly 'mass production' nature of the pottery (ibid., 114).

Malygin et al. say little directly about the context of pottery production, but they see the hand-made tradition ending at the close of the 10th or the beginning of the 11th century $(2006,76)$, followed by a fundamental change within the wheel-turned tradition in the middle and 2nd half of the 12th century (Spits 12-11) (ibid.). At that date, many news forms appear, and rims with ledges for lids appear for the first time. They also note the use of finer temper from the late 13th or early 14th century, and the use of white-firing clay at the end of the 15th century (ibid., 55). Both of these changes might be linked to increasing specialisation; the former because it is a precondition for wheel-throwing, and the latter because it requires a higher firing temperature.

Brorsson (pers. comm.) stresses the importance of the introduction of wheel-throwing (in contrast to wheel-turning) as an indicator of the change from household handicraft to professional workshop production. He links this to the switch from gruss to sand temper, which starts in the 13th century (see above), and notes that this seems to be contemporary with the Duboshin glazed wasters. He raises the possibility of the acquisition of a package of technological advances (glazing, wheel-throwing, finer temper) from alien pottery in the nearby Gotland or German quarters. However, he also notes that the glazed sherds themselves are gruss-tempered, and therefore presumably not from wheel-thrown vessels. 


\section{Discussion}

In the context of the medieval ceramics of north-west Russia, some potential indicators of craft specialisation have proved to be more useful than others. Virtually no evidence has been found of centres of production, leaving open such questions as the use of purposebuilt kilns (in contrast to bonfires, temporary kilns or the use of domestic stoves), their possible nucleation, and their location in rural or urban areas.

The standardisation approach has been of limited use; reliance on a typology devised for chronological purposes means that diversity cannot be expressed through counts of types, while the variability of measured dimensions (e.g. rim diameter) shows no patterning either between types or through time. Indeed, there are reasons to suggest that craft production here might be expected to show greater diversity in this respect, reversing the usual argument. Only decoration seems to hold some promise; there are significant trends in the proportion of pots being decorated, the extent of decoration on each pot, and the number of decorative styles in use at the same time, at both Novgorod and Pskov. Calculations of the overall scale of production are of necessity speculative, and in many circumstances would not be possible at all - only the particular circumstances of Novgorod make this approach even remotely realistic. Some idea of the reliability of such estimates can be obtained by calculating their margins of error, which are typically and expectedly large. Nevertheless, they are adequate to show that the consumption of pottery in Novgorod seems low relative to the population, despite the apparently large quantities retrieved in excavations. This is perhaps only to be expected in a culture in which wood 
is the predominant raw material, and in which wooden vessels and containers are abundant. The most useful indicator here is that of the potting technology, in which evidence of clay preparation, forming, decorating, and firing can all contribute to an understanding of the organisation of production.

The general type of clay used (the so-called 'grey-brown' clay (Kildyushevskii 2006, 82) seems consistent over the region and throughout the period, although there was much variation between and even within local sources (Brorsson, pers. comm.). Clay from more restricted sources (the 'red' and 'white' clays (Kildyushevskii 2006, 82) start to appear at the end of the period (late 15th century), perhaps reflecting the growing dominance of Moscow over the region at that time. The grey-brown clay (unlike the red and the white) requires considerable temper (either natural or deliberately added) to make it workable (Kildyushevskii 2006, 83). The same materials (various grades of sand, and gruss) are used at both Novgorod and Pskov, but there are important chronological differences in their relative importance at the two towns - gruss dominates the early production at Novgorod, with sand becoming important only from the 13th century, while at Pskov the position is almost reversed. This shows one extent to which local variation is possible within the regional tradition. As for forming, pots that are completely hand-made are known in Novgorod only in the 10th century (pots of this date from Pskov are not reported on in Kildyushevskii 2006), while wheel-throwing is clearly evident at Pskov from the 16th century onwards and Novgorod is presumed to be similar. Wheel-turning is the norm throughout most of the period at both Novgorod and Pskov. The timing of the introduction of full wheel-throwing is debatable; it may be reflected in the use of sand 
rather than gruss for tempering, but the reverse trend at Pskov seems to make this less likely, and the wheel-turning of coil-built pots is thought to continue there until the late 15th century (Kildyushevskii 2006, 84). More direct evidence for wheel-throwing is difficult to obtain because of selective collection policies. Glazing, which is a strong indicator of specialist potters, does not occur until the 16th century. Trends in form types are less likely to reflect production techniques than functional requirements, such as the introduction of lid-bearing rims at Novgorod in the second half of the 12th century, or the trend from tall cooking pots with conical bodies to squatter ones with rounded bodies noted at Pskov (the better to fit into the newer style of oven, see Kildyushevskii 2006, 114). The trends in decoration are towards simplicity and ease of application, both suggestive of increasing intensity of production and decreasing 'personalisation' of the pottery. The discovery of associations between two specific rim forms and rouletting and wavy line decoration respectively (Orton 2006, 124) suggests the possibility of a more decoration-based definition of types, which might be related to different production centres, and may open up new directions of analysis. Finally, there are two episodes of technological (in contrast to functional or stylistic) innovation: the apparently short-lived experiment with glazed wares at the Duboshin site in the later 13th century, and the period of use of a naturally sand-tempered white-firing clay at Novgorod in the 13th and particularly the early 14th century (Malygin and Orton 2001, 60). The former appears to have no direct effect on subsequent production (unless as part of a package which includes the introduction of wheel-throwing), while the latter gives rise to new rim forms (the 'folded' rims) and a decorative technique (a combination of horizontal grooves and 
'stabbing'), which continue until the end of the period, although the use of this fabric does not.

What does all this evidence imply for the social organisation of the production of medieval pottery in the region? The beginning and end of the transition from domestic to specialised production are easy to pin down. The hand-made, highly decorated and individually distinctive pottery that dies out in the 10th century has all the signs of domestic production, while the combination of wheel-throwing, fine white-firing clay, and glazing in the 16th and 17th century clearly indicate fully specialised production. The question is whether the progression through the period was gradual or took place in one or more distinct steps. Key to this is the date of the introduction of wheel-throwing. The evidence for the introduction of the fast wheel at Novgorod is indirect, depending on the introduction of sand-tempered pottery in the late 13th century. But, because the absence of gruss is a precondition for wheel-throwing, it does not mean that wheel-throwing actually took place at this time. Also, since the use of gruss in Novgorod continued alongside sand until the end of the 15th century, wheel-throwing (if it took place) must have been practised in parallel with the earlier coiling method for some two centuries. The quantity of gruss-tempered pottery appears to peak in the 13th century, but it is still substantial in the 14th and 15 th centuries. This might seem to rule out the contemporary use of wheel-throwing, but the parallel production of similar forms in coiled and wheelthrown fabrics, both by specialist potters, is known elsewhere, for example in the production of BB1 and BB2 pottery in Roman Britain (Tyers 1996, 182-7). However, the contemporary trend from sand to gruss at Pskov makes this parallel usage less likely at 
Novgorod, and strengthens the argument that full wheel-throwing did not develop there until the late 15 th or 16 th century.

A more likely starting date for specialised craft potting is in the mid-12th century, with the emergence of a distinct local style at Pskov and a new range of simply-decorated forms at Novgorod. It could have developed through increasing intensity of production in certain households, gradually deriving more of their income from potting and less from other activities. Certainly, there is enough confidence by the late 13th century for attempts at innovation to take place, even if only partly successfully. The location of these potters is still unknown; their presence in the towns cannot yet be ruled out, but rural locations become increasingly likely as successive excavations fail to find structural evidence for potting. The existence of itinerant potters, exploiting local resources on a cyclical basis, is another possibility. The quantities of pottery being produced from the mid-12th century onwards would require the operation of more than one kiln even if worked intensively, but whether they were nucleated into a potting quarter or village, or dispersed throughout settlements or their hinterlands, remains unknown.

\section{Implications for theory}

This study has revealed two major weaknesses in the theory that was used to underpin it. In both cases, the concept of diversity or standardisation has proved to be something of a broken reed. First, no general or chronological typology of pottery forms can be expected to establish the level of diversity in an urban assemblage, even on a relative basis. To achieve a typology that reflects the intentions of an individual potter would of itself be 
extremely difficult; add to this the need to encompass the products of several producers over a period of time, and the need to work from mainly fragmentary material, and it becomes virtually impossible. Second, the use of measured dimensions as an indicator of standardisation can actually be misleading, since there are circumstances in which the products of specialist potters could show greater variability than those of domestic producers. This could occur, for example, if specialist potters were producing pots of a particular form in a range of sizes. There is a technique for the detection of the basic units of measurement of which such sizes would be multiples (the cosine quantogram, see Baxter 2003, 232), but its use here would be complicated by the natural variation in the material and the problem of obtaining precise estimates of measurement such as rim diameters, from sherds that are only a fraction of a rim. It would, however, be an interesting line of future research.

\section{Suggestions for future work}

A large-scale search for centres of production is probably not a practical proposition, and we will have to continue to hope for chance discoveries. Further microscopic work would probably be premature at this stage; the main fabrics have now been characterised and can be recognised macroscopically. More detailed study of detailed technological characteristics, such as the methods of attaching different parts of vessels, can be expected to help distinguish between the products of different centres, and perhaps even between potters. This could be greatly assisted by the further development of a system for describing decoration, taking account of the different techniques used, the way in which they are combined, and their location and extent on a pot. Both studies would require 
more comprehensive retention of material; for example, bases often reveal important technological information. Questions of the scale of use, and trends in it, can be answered through the construction of quantified sequences based on standardised and reproducible typologies of fabric, form and decoration. Such sequences could be compared, both within and between settlements, to examine the distribution of the products of particular sources. The extent to which this will be possible will depend on the choice of sites for future excavations, a choice that is however not likely to be driven by ceramic concerns. The aim must therefore be to draw up an agenda of research questions and tasks, which can be implemented as and when the opportunity arises. 


\section{Bibliography}

Aleksandrovskaya, E.I., Aleksandrovsky, A.L., Gaidukov, P.G. and Krenke, N.A. 2001. 'Woodland, meadow, field and town layout: the evidence from analyses of the earliest cultural deposits and buried soil in Novgorod' in Brisbane, M. and Gaimster, D. (eds) Novgorod: the Archaeology of a Russian Medieval City and its Hinterland. British Museum Occasional Papers 141, 15-21.

Allan, J.P. 1984. Medieval and Post-medieval Finds from Exeter, 1971-1980. Exeter Archaeological Reports, 3.

Baxter, M. 2003. Statistics in Archaeology. London: Hodder Arnold.

Blackman, M.J., Stein, G.J. and Vandiver, P.B. 1993. 'The standardization hypothesis and ceramic mass production: technological, compositional, and metric indexes of craft specialization at Tell Leilan' American Antiquity 58 (1), 60-80.

Bobrinskii, A.A. 1978. Goncharstvo Vostochnoi Yevropy (Pottery making in Eastern Europe), Moscow.

Costin, C.L. 1991. 'Craft specialization: issues in defining, documenting, and explaining the organisation of production' in Schiffer, M.B. (ed.) Archaeological Method and Theory, 3, 1-56.

Costin, C.L. and Hagstrum, M.B. 1995. 'Standardization, labor investment, skill, and the organization of ceramic production in Late Prehispanic Highland Peru' American Antiquity 60 (4), 619-639.

Cotter, J. P.1997. A Twelfth-century pottery kiln at Pound Lane, Canterbury: Evidence for an immigrant potter in the late Norman period, Canterbury Archaeological Trust Occasional Paper 1. 
Eerkens, J.W. and Bettinger, R.L. 2001. 'Techniques for assessing standardization in artefact assemblages: can we scale material variability?' American Antiquity 66 (3), 493-504.

Feinman, G.M. 1999. 'Rethinking our assumptions: economic specialization at the household scale in ancient Ejutla, Oaxaca, Mexico' in Skibo, J.M. and Feinman, G.M. (eds) Pottery and People: a dynamic interaction, 81-98. Salt Lake City: University of Utah Press.

Gaimster, D. 2001. 'Pelts, pitch and pottery: the archaeology of the Hanseatic trade in medieval Novgorod' in Brisbane, M. and Gaimster, D. (eds) Novgorod: the Archaeology of a Russian Medieval City and its Hinterland. British Museum Occasional Papers 141, 67-78.

Gaimster, D.R. 2006. 'Pottery imported from the west: reception and resistance' in Orton, C.R. (ed.) The Pottery from Medieval Novgorod and its Region, 135-143. UCL Press: London.

Goryunova, V.M. 2006. 'Early wheel-turned pottery from Ryurik Gorodishche (10th century) and certain questions connected with its synchronisation with the pottery of Novgorod and Staraya Ladoga' in Orton, C.R. (ed.) The Pottery from Medieval Novgorod and its Region, 31-51. London: UCL Press.

Hagstrum, M.B. 1985. 'Measuring prehistoric ceramic craft specialization: a test case in the American Southwest' Journal of Field Archaeology 12, 65-75.

Khoroshev, A.S., Sorokin, A.N. and Petrov, M.I. 2001. 'Property layout in medieval Novgorod in the 10th to 15 th centuries' in Brisbane, M. and Gaimster, D. (eds) 
Novgorod: the Archaeology of a Russian Medieval City and its Hinterland. British Museum Occasional Papers 141, 67-78.

Kildyushevskii, V.I. 2006. 'Pskov pottery in the 12th to 16th centuries' in Orton, C.R. (ed.) The Pottery from Medieval Novgorod and its Region, 79-115. London: UCL Press.

Kolchin, B.A. 1985. Drevnyaya Rus: gorod, zamok, selo (Medieval Russia: towns, castles and rural settlement). Rybakov, B.A. (general ed.) The Archaeology of the USSR, vol. 15. Moscow: Nauka.

Koval, V.Y. 2006 'Eastern pottery from the excavations at Novgorod' in Orton, C.R. (ed.) The Pottery from Medieval Novgorod and its Region, 161-192. London: UCL Press.

Malygin, P.D., Gaidukov, P.G. and Stepanov, A.M. 2006. 'Typology and chronology of Novgorod pottery of the 10th to 15th centuries (based on material from the Troitsky XI excavation)' in Orton, C.R. (ed.) The Pottery from Medieval Novgorod and its Region, 53-77. London: UCL Press.

Malygin, P.D. and Orton, C.R. 2001 'Approaches to a large, relatively uniform asssemblage of ceramics' in Brisbane, M. and Gaimster, D. (eds) Novgorod: the Archaeology of a Russian Medieval City and its Hinterland. British Museum Occasional Papers 141, 59-66.

Orton, C.R. 1985 'Diffusion or impedance - obstacles to innovation in medieval ceramics' Medieval Ceramics 9, 21-34.

Orton, C.R. 2002 'Never under-estimate the power of a model' in Burenhult, G. (ed.) Archaeological Informatics: Pushing the Envelope. CAA2001 Computer 
Applications and Quantitative Methods in Archaeology BAR Int Ser 1016 (2002) 495-9.

Orton, C.R. 2006 'Handling large urban assemblages and their statistics' in Orton, C.R. (ed.) The Pottery from Medieval Novgorod and its Region,117-126. London: UCL Press.

Peacock, D.P.S. 1982. Pottery in the Roman World: an Ethnoarchaeological Approach. London: Longmans.

Peregrine, P. 1991. 'Some political aspects of craft specialization' World Archaeology 23 (1), 1-11.

Plokhov, A.V. 2006. 'Hand-made pottery from Ryurik Gorodishche and Novgorod' in Orton, C.R. (ed.) The Pottery from Medieval Novgorod and its Region, 13-30. London: UCL Press.

Rud, O.A. 2006. 'An attempt to classify the decoration of Novgorod medieval pottery using material from Troitsky excavation XI (Spits 22-10)' in Orton, C.R. (ed.) The Pottery from Medieval Novgorod and its Region, 127-133. London: UCL Press.

Rybina, E.A. and Khoroshev, A.S. (compilers and eds) 2002. Archaeologists of Novgorod the Great: a biographical manual. Novgorod: Novgorod State Museum and the Centre for the Organisation of Archaeological Research in Novgorod.

Sinopoli, C. 1999. 'Levels of complexity: ceramic variability at Vijayanagara, South India' in Skibo, J.M. and Feinman, G.M. (eds) Pottery and People: a dynamic interaction, 115-136. Salt Lake City: University of Utah Press.

Tyers, P.A. 1996 Roman Pottery in Britain. London: B.T. Batsford, Ltd. 
Van der Leeuw, S. 1977. 'Towards a study of the economics of pottery making' in van Beek, B.L., Brandt, R.W. and Groenman-van Waateringe, W. (eds) Ex Horreo, 68-76. Institute of Pre- and Proto-History, University of Amsterdam, The Netherlands. 